\title{
Determination of the Rheological Parameters of Invert Emulsion Drilling Fluid in Real Time using Non-Linear Regression Technique
}

\author{
Elkatatny SM1*, Zidan $\mathrm{K}^{1}$ and Mahmoud $\mathbf{M}^{1}$ \\ 1Department of Petroleum, King Fahd University of Petroleum \& Minerals, Dhahran, \\ Saudi Arabia
}

*Corresponding author Salaheldin Mahmoud Elkatatny, King Fahd University of

\section{Research Article}

Volume 1 Issue 1

Received Date: February 18, 2017

Published Date: March 22, 2017

Petroleum \& Minerals, Dhahran, Saudi Arabia, Tel: 0594663692; Email: elkatatny@kfupm.edu.sa

\section{Abstract}

Rheological parameters are the key factor for hydraulic calculations and hole cleaning efficiency in the drilling operations. Rheological parameters include mud density, plastic viscosity, apparent viscosity, and yield point. Rheological parameters should be measured or estimated during the real operation to determine the actual equivalent mud circulation density, surge and swab pressures, hydraulic calculations, and hole cleaning efficiency. The mud rheological properties can be obtained from laboratory measurements. These measurement scan be divided into two types; the first one is simple testing such as mud density and Marsh funnel viscosity. The second set of experiments is the rheological properties measurements. Onsite, Marsh funnel viscosity and fluid density are measured frequently (every 10 to 20 minutes) to monitor the change of the drilling fluid properties while as the rheological properties are measured twice a day.

In this paper a new model was developed to estimate the rheological parameters of invert emulsion-based drilling fluid using Marsh funnel viscosity and mud density. Multiple nonlinear regression technique was used to develop the new model. 6,000 data points from field measurements of the Marsh funnel viscosity, mud density, plastic viscosity, and yield point, were used in this study to develop the new model. The new model can be used to predict the following properties of the drilling fluid; viscometer readings at 300 and 600, plastic viscosity, yield point, apparent viscosity, power law index, and consistency index. All the previous parameters will be predicted using only Marsh funnel time and drilling fluid density. The developed models consists of six correlations that can be used to estimate the rheological properties with an average absolute error less than $4 \%$ and a correlation coefficient greater than 0.95 based on the Marsh funnel time and drilling fluid density. These correlations can be used to prepare the input parameters for hole cleaning and hydraulic calculations in real time. Applying this inexpensive technique will help drilling engineers predict any problem before it happens such as pipe sticking, sage issues, and loss of circulation.

Keywords: Hydraulics; Invert emulsion; Rheological parameters; Plastic viscosity; Yield point; Hole cleaning. 


\section{Petroleum \& Petrochemical Engineering Journal}

\section{Introduction}

P Drilling fluid is the key element in the drilling operations. It has many functions such as controlling the formation pressure, carrying the drilled-cutting form down hole to the surface, transferring information from down hole to surface, cooling andlubricating the drill string and the drill bit, and form ideal filter cake for wellbore stability purposes. In order to perform these functions, the drilling fluid should contain inert solids for density control, reactive solids for viscosity control, and polymers for filtration control [1]. This complex nonNewtonian fluid mixture will be used to drill different wells, such as vertical, deviated, horizontal, and extended reach wells.

Invert emulsion is a type of oil based drilling fluid that has $50 \%$ water ratio. This type of oil is low toxicity and oil is the continuous phase while water with $\mathrm{CaCl} 2$ is the dispersed phase. Calcium chloride is used to increase the salinity of water and prevent any migration of water molecules from solution to formation. Invert emulsion is commonly used in the drilling operations in oil and gas industry [2].

Different instruments are used to determine the fluid properties, such as mud balance, Fann 35 viscometer, API filter press, Marsh Funnel, and high-pressure high temperature filter press. These measurements can be performed in the laboratory and it takes long time, on the well site, some of these instruments are not available and will take long time which is not available during the real drilling operation. The drilling fluid should be designed to have viscosity to sweep the cutting to the surface. This term of viscosity is called plastic viscosity (PV) according to Bingham model and consistency index (k) according to Power low model. In addition, the drilling fluid should have a yield stress which is called yield point (YP) according to Bingham model and flow behavior index (n) according to Power Low model.Drilling fluid rheology plays a key factor in many aspects of the drilling operations. It can affect the following parameters; hydraulic calculations, hole cleaning, and sag tendency of weighting material (separation and settling of the weighting material), Tehrani [3]. The ratio of $\mathrm{YP} / \mathrm{PV}$ is very important for hole cleaning and preventing common problems in the drilling operations such as pipe sticking, loss of circulation, and sagging effect. The drilling fluid should be designed to prevent any sag issue and fluid loss problem $[4,5]$. The formation damage can be minimized by using microemuslion; oil based drilling fluids, and inverted emulsion drilling fluid [6]. The invasion of the inverted emulsion drilling fluid system is very low compared to the water based drilling fluids because of the high viscosity of the oil and this will minimize the damage caused by the drilling fluid invasion. In turn, the need for well stimulation operation after drilling will be minimized if not eliminated.

The knowledge of rheological properties of the drilling fluid, which are generated from suspended solids and rheology control additives, is highly important in the drilling operations [7]. Each parameter plays an important role in the success of drilling operations. Zamora and Power stated that the yield stress is the most important factor for hole cleaning problems, sag issue, and surge and swab pressures [8]. They introduced a relation between the yield stress $\left(\tau_{\mathrm{y}}\right)$ and the yield point (YP) for different drilling fluid types. They concluded that the acceptable range of $\tau_{y} / \mathrm{YP}$ ratio is $0.5-0.68$ for synthetic-based mud, $0.48-0.59$ for oil-based mud, and $0.2-0.4$ for water-based mud. The $\tau_{y} / Y P$ is an important parameter to describe the mud rheology.The normal operation on the well site is to perform a complete test for the drilling fluid at morning and evening. Only mud density and Marsh funnel viscosity are measured frequently to give an indication of the change in drilling fluid properties. Marsh funnel is used to obtain the time in seconds required to fill a $950 \mathrm{~cm}^{3}$ volume cup with drilling fluid [9]. Marsh funnel can be used to estimate many parameters such as fluid yield stress. This technique is inexpensive and it gives accurate results as Fann 35, [10]. The determination of rheological parameters is very important for pressure loss calculations. Other factors should be taken into consideration for hydraulic calculations such as drill cuttings. Zhang studied the effect of solid content in the calculation of the pressure loss in the annulus. Zhang et al. concluded that at low flow rates, the drilling fluid solid contentaffected the pressure profile while at high flow rateitseffect diminished [11]. Due to this effect, the bottom hole pressure may increase when the pump stopped. Solid effect should not be neglected in hydraulic calculations because it maycause pressure loss greater than the friction pressure loss. In addition to that, the hole shape has high effecton hydraulic performance and hole cleaning. Noncircular holes may have lower pressure gradient and better hole cleaning than circular holes [12]. In the literature, only few correlations were found to determine the apparent viscosity from the rheometer or Marsh funnel viscosity. In this paper we used 6000 data points collected from actual field measurements of invert emulsion drilling fluid to develop the correlations to determine the drilling fluid rheological properties. Also we will compare the developed correlations with the ones existed in the literature to show the accuracy of the developed correlations. 


\section{Petroleum \& Petrochemical Engineering Journal}

\section{Apparent Viscosity from Marsh Funnel}

Based on 26 drilling fluids, a graphical method was developed to estimate the apparent viscosity of these drilling fluids as a function of Marsh funnel and the Stormer viscometer [13]. Equation 1 shows the relationship of the apparent viscosity as a function of Stormer speed and some constants.

$A V=\frac{K}{R^{x}}(1)$

$\begin{array}{cc}\text { AV } & \text { apparent viscosity, } \mathrm{cP} \\ \mathrm{R} & \text { Speed of Stormer cylinder, rpm } \\ \mathrm{X} & \text { exponent related to initial shear stress } \\ & \text { constant (x and K can be determined from } \\ \mathrm{K} & \text { the plot of Stormer viscosity measurement vs the } \\ & \text { viscometer speed) }\end{array}$

Pitt developed a correlation to convert Marsh funnel time to effective viscosity of drilling fluids as a function of drainage time and mud weight. He built a numerical simulation model of the flow behavior of the drilling fluid in Marsh funnel was built. The following correlation was developed to estimate the effective viscosity of the drilling fluid, Equation 2 [14].

$A V=D(T-25)(2)$

Almahdawi introduced a new model to estimate the apparent viscosity of drilling fluids using Marsh funnel time and fluid density [15]. Several samples of drilling fluids were prepared with different quantities of barite, bentonite, and other additives in order to give various rheological behaviors. Fluid density and Marsh funnel time of the samples were measured. The results were used to fit Equations 3 and 4. They concluded that Equation 3 related the apparent viscosity to Marsh funnel time gives has accurate results compared to Equation 4 . They found out that the constant of 28 is more appropriate than 25, obtained by Pitt [14].

$$
\begin{gathered}
A V=-0.0118 * T^{2}+1.6175 * T-32.168(3) \\
A V=D(T-28)(4)
\end{gathered}
$$

Where

$$
\begin{array}{cc}
\text { AV } & \text { apparent viscosity, } \mathrm{cP} \\
\mathrm{D} & \text { Fluid density, } \mathrm{g} / \mathrm{cm}^{3} \\
\mathrm{~T} & \text { Marsh funnel time, sec. }
\end{array}
$$

The objective of this paper is to develop new empirical correlations of plastic viscosity, yield point, apparent viscosity, flow behavior index, and flow consistency index.

\begin{tabular}{|c|c|c|c|c|}
\hline \# & $\begin{array}{l}\text { Density } \\
\left(\mathrm{lb} / \mathrm{ft}^{3}\right)\end{array}$ & $\begin{array}{c}\mathrm{T} \\
\text { (second/quart) }\end{array}$ & $\begin{array}{l}\text { PV } \\
\text { (cP) }\end{array}$ & $\begin{array}{c}\text { YP } \\
\left(\mathrm{lb} / 100 \mathrm{ft}^{2}\right)\end{array}$ \\
\hline 1 & 57 & 44 & 11 & 16 \\
\hline 2 & 57 & 45 & 11 & 19 \\
\hline 7 & 70 & 65 & 22 & 21 \\
\hline 8 & 71 & 70 & 26 & 23 \\
\hline 9 & 72 & 71 & 22 & 21 \\
\hline - & - & - & - & - \\
\hline 6000 & 110 & 85 & 40 & 26 \\
\hline
\end{tabular}
These correlations will be developed for invert emulsionbased drilling fluid based on the analysis of 6000 actual field data measurements. Table 1 lists the main available parameters for this study.

Table 1: Field data for invert emulsion based mud.

The importance of this research is the real time determination (every 10 to 15 minutes)of the hydraulic calculations, surge and swab pressure, hole cleaning efficiency, and equivalent circulation density based on the rheological parameters that will be determined from the mud density and Marsh funnel viscosity. Real time monitoring of different drilling parameters will help early detect and mitigate the possible drilling problems.

\section{Nonlinear Curve Fitting}

A complete analysis for the invert emulsion drilling fluid was performed to predict the rheological properties of the drilling fluid and we compared the estimated values to the given value. Apparent viscosity, the viscometer reading at $600 \mathrm{rpm}\left(\mathrm{R}_{600}\right)$, and the viscometer reading at $300 \mathrm{rpm}\left(\mathrm{R}_{300}\right)$ can be determined from the available data using Equations 5 to 7.

$$
\begin{gathered}
R_{300}=Y P+P V(5) \\
R_{600}=P V+R_{300}(6) \\
A V=\frac{R_{600}}{2}(7)
\end{gathered}
$$

The flow behavior index and flow consistency index are calculated using Equations 8 and 9.

$$
\begin{array}{r}
n=3.32 * \log \left(\frac{R_{600}}{R_{300}}\right) \\
K=\frac{R_{600}}{1022^{n}}(9)
\end{array}
$$

Using non-linear curve fitting technique, Equation10 was developed to predict the viscometer reading at 300 rpm using the drilling fluid density and Marsh funnel viscosity.The average absolute error of the estimated values of $R_{300}$ was calculated based on the actual one and 


\section{Petroleum \& Petrochemical Engineering Journal}

it was 2.82 and the correlation coefficient was $0.96\left(\mathrm{R}^{2}=\right.$ 0.92), as shown in Figure 1.

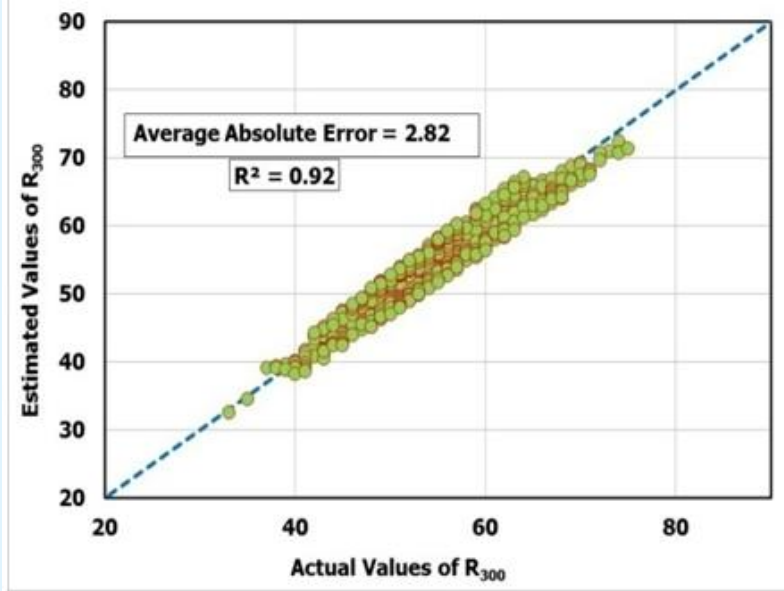

Figure 1: Estimated value of R300 vs. actual value of R300 using nonlinear regression technique.

The same technique was used to estimate the viscometer reading at $600 \mathrm{rpm}$ based on the fluid density and Marsh funnel time. Equation 11 was developed to estimate $\mathrm{R}_{600}$ with an average absolute error of 3.28 and a correlation coefficient of $0.96\left(\mathrm{R}^{2}=0.93\right)$, Figure 2. In order to predict the parameters for power low model, Equation 12 was developed based on fluid density and Marsh funnel time.

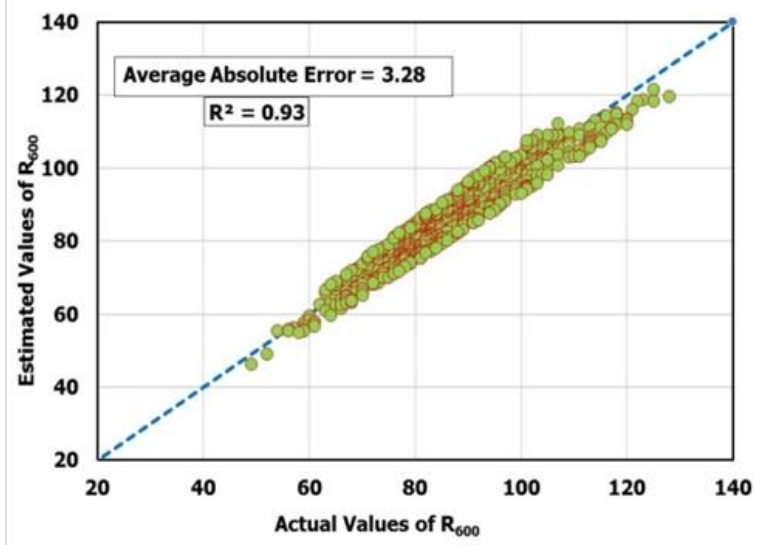

Figure 2: Estimated value of $R_{600}$ vs. actual value of $R_{600}$ using nonlinear regression technique.

Figure 3 shows the comparison of estimated values of $n$ with the actual ones with an average absolute error of 1.4 and a correlation coefficient of $0.96\left(R^{2}=0.92\right)$.

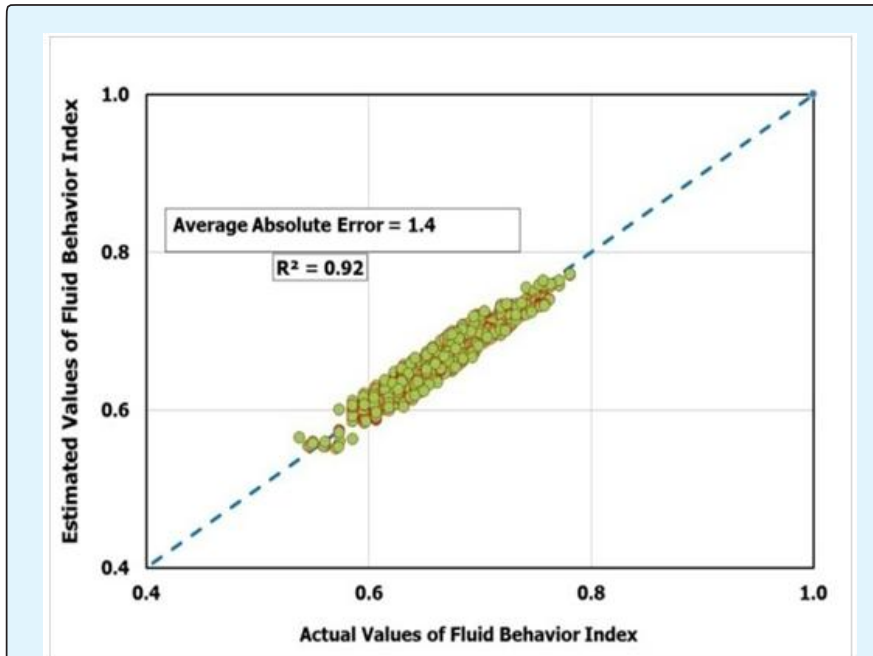

Figure 3: Estimated value of flow behavior index vs. actual value using nonlinear regression technique.

$$
\begin{gathered}
R_{300}=19.0001 * D * \log (T-35.748)+12.896(10) \\
R_{600}=37.2748 * D * \log (T-30.80)+1.1638(11) \\
\\
n=0.1193 * D * \log (T-11.249)+0.3459(12) \\
\mathrm{D} \\
\mathrm{T}
\end{gathered}
$$

\section{Validation of Developed Correlations}

To validate the developed correlations, plastic viscosity and flow consistency index were calculated based on the estimated values of $R_{300}, R_{600}$, and flow behavior index. The obtained results were plotted vs. the actual measured data to investigate the accuracy of the developed correlations. Plastic viscosity was calculated based on Equation 6. Figure $4 \mathrm{a}$ shows the comparison of the calculated values of plastic viscosity based on estimated values of $R_{300}$ and $R_{600}$ with the actual values of plastic viscosity.

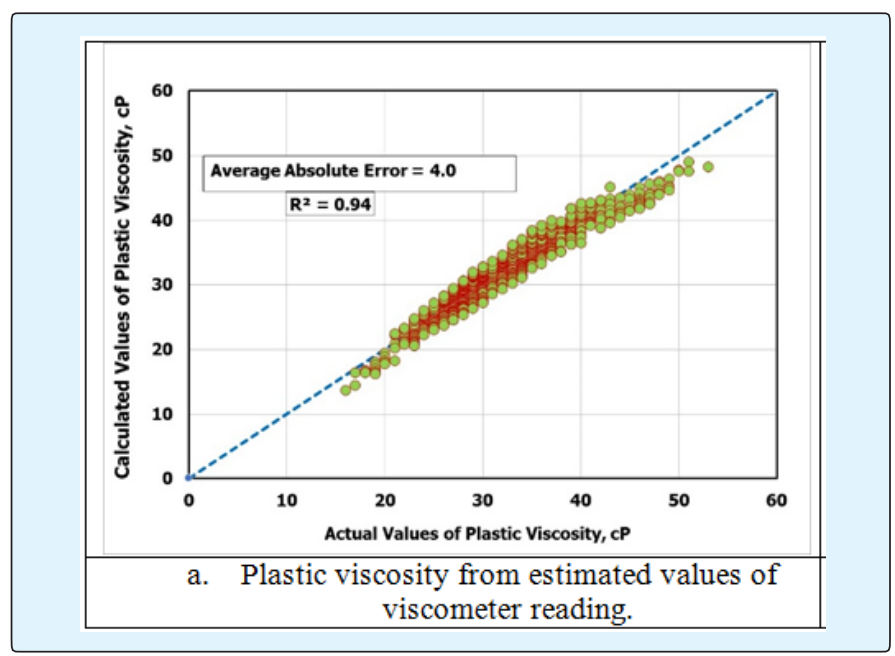




\section{Petroleum \& Petrochemical Engineering Journal}

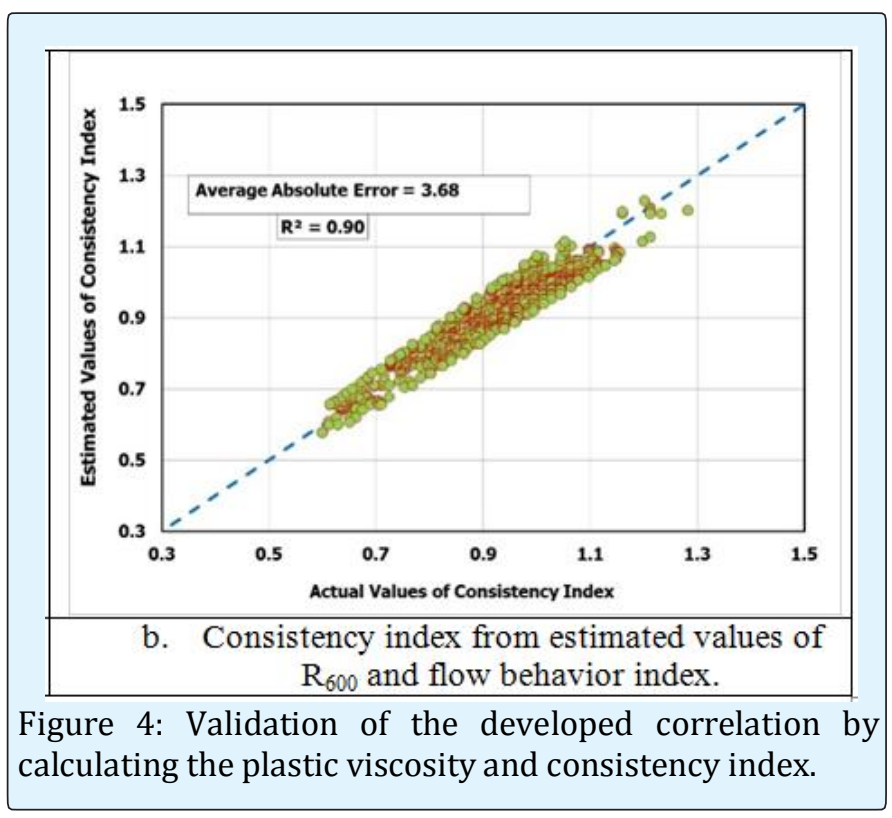

It was found that the average absolute error was $4.0 \%$ and the correlation coefficient was $0.97\left(\mathrm{R}^{2}=0.94\right)$ comparing the actual and calculated values of the plastic viscosity. Flow consistency index was calculated based on the estimated value of flow behavior index and viscometer reading at $600 \mathrm{rpm}$, Equation 9. Figure 4b shows that the average absolute error of $3.68 \%$ and the

correlation coefficient of $0.95\left(\mathrm{R}^{2}=0.90\right)$ comparing the calculated value of flow consistency index with the actual one.

To estimate the yield point, plastic viscosity, and apparent viscosity directly from the Marsh funnel time and fluid density, non-linear regression technique was used and to obtain Equations 13-15 for yield point, plastic viscosity, and apparent viscosity, respectively. The same results were obtained using Equations 5-7 based on the estimated values of the rheometer readings. The importance of developed equations (13-15) is the directed estimation of these parameters from the Marsh funnel viscosity and mud density which will make the programming of these models easy and simple for the real time prediction.

$$
\begin{gathered}
Y P=1.5492 * D * \log (T-30.9)+18.84(13) \\
P V=17.735 * D * \log (T-30.9)-7.979(14) \\
A V=18.833 * D * \log (T-30.9)+0.9186(15)
\end{gathered}
$$

$\mathrm{D}$

T

YP

PV

AV drilling fluid density, $\mathrm{g} / \mathrm{cm}^{3}$

Marsh Funnel time, second/quart yield point, $\mathrm{lb} / 100 \mathrm{ft}^{2}$ plastic viscosity, $\mathrm{CP}$ apparent viscosity, $\mathrm{CP}$
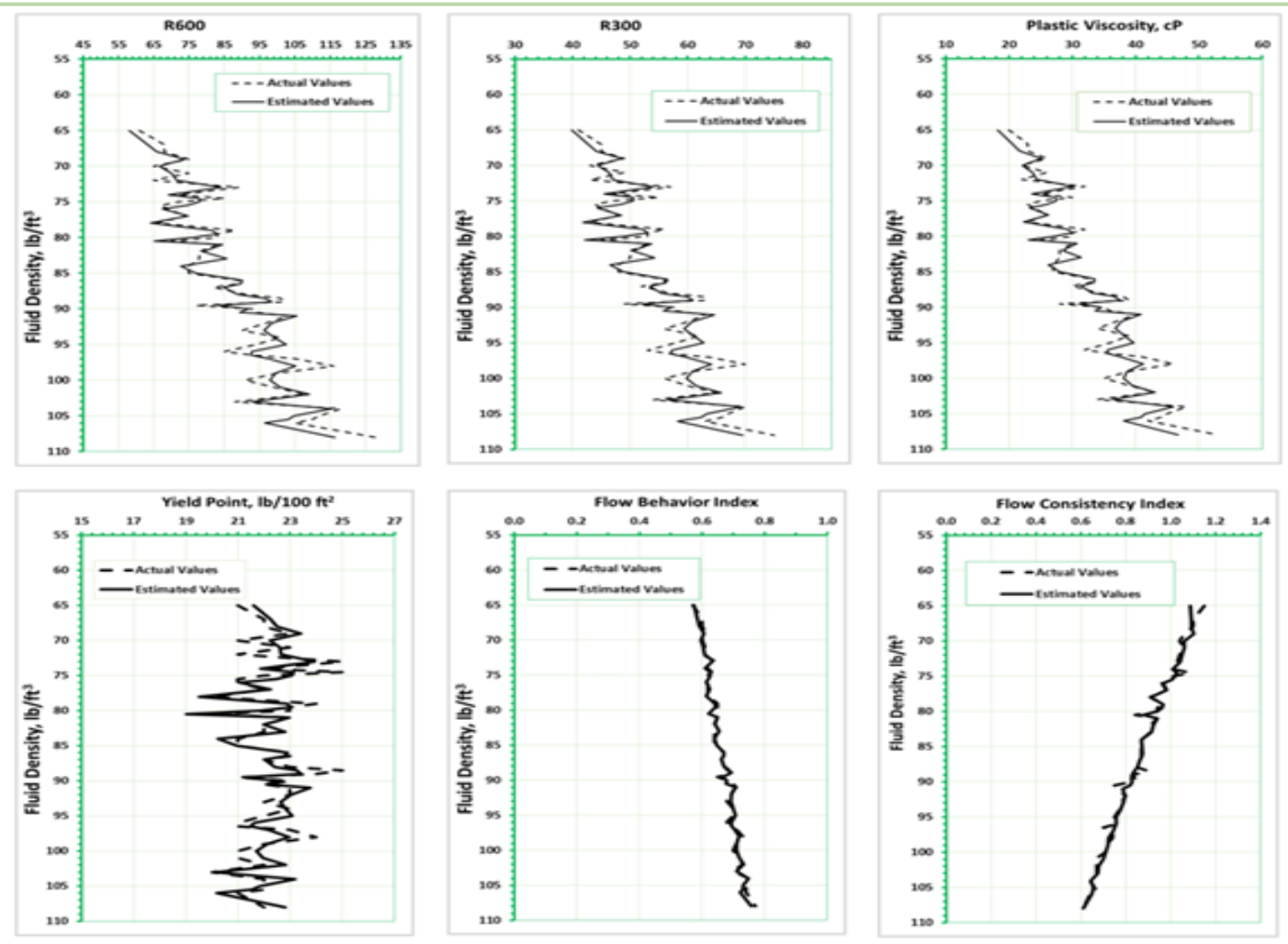

Figure 5: Comparison of the rheological parameters over a wide range of fluid density. 


\section{Petroleum \& Petrochemical Engineering Journal}

Figure 5 shows the comparison of the predicted values of the rheological parameters with the actual ones for a wide range of density (60 to $110 \mathrm{lb} / \mathrm{ft}^{3}$ ). Once the rheological parameters are available, Bingham model or Power low model can be usedfor drillinghydraulics calculations. Knowing the actual drilling parameters, such as rate of penetration, the pipe rotational speed, flow rate, and pump pressure, the hole cleaning efficiency can be determined based on the estimated values of the rheological parameters.

\section{Validating the Apparent Viscosity Correlations with Previous Correlations}

As explained in the introduction part, there are only two available correlations in the literature that discussed the prediction of the apparent viscosity from the mud density and Marsh funnel viscosity. In this section we will compare the developed correlation of the apparent viscosity with Pitt's and Almahdawi et al. correlations $[14,15]$.

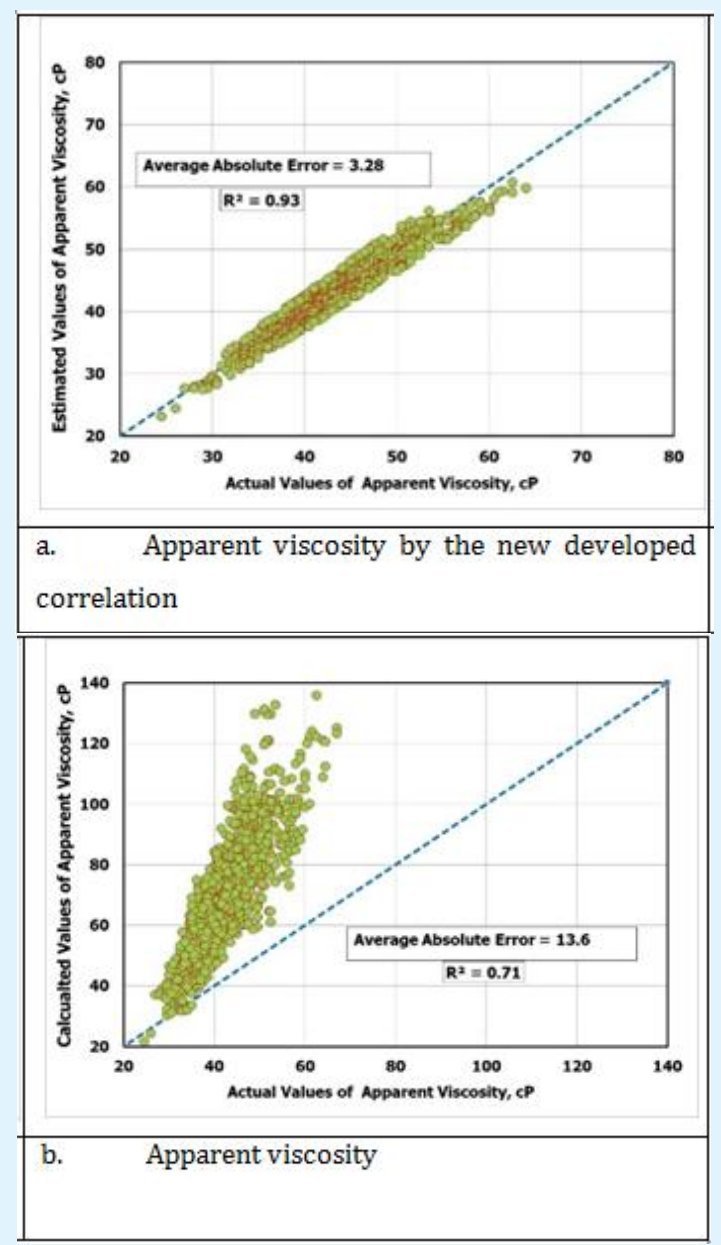

Figure 6: Comparison of estimated values of apparent viscosity by the new correlation with model.
Figure 6 shows that the average absolute error was $3.28 \%$ and the correlation coefficient was $0.96\left(\mathrm{R}^{2}=0.3\right)$ using Equation15 to estimate the apparent viscosity based on mud density and Marsh funnel viscosity. Pitt correlation overestimated the apparent viscosity as the average absolute error was $13.6 \%$ and the correlation coefficient was $0.84\left(\mathrm{R}^{2}=0.71\right)$. Almahdawi et al. correlation yielded an average absolute error of $43 \%$. Based on these results, it can be concluded that the developed correlation is accurate enough to predict the apparent viscosity with the highest correlation coefficient and the lowest average absolute error compared to previously developed correlation. This is the first time to predict other rheological parameters such as plastic viscosity, yield point, flow behavior index, and flow consistency index based on mud balance and Marsh funnel viscosity. The developed correlations have a high correlation coefficient $(>0.95)$ and low average absolute error $(<4 \%)$.

\section{The Importance of Predicting Drilling Fluid Properties in Real Time}

The real time prediction of power law index, consistency index, plastic viscosity, yield point, and apparent viscosity from the Marsh funnel and drilling fluid density, will help monitor the drilling process. For example the hole cleaning efficiency can be determined during drilling in real time based on the predicted parameters using the developed model. The prediction of hole cleaning efficiency will prevent several drilling problems such as high drag, torque, and pipe sticking. Once the power law index is determined and consistency index in real time using the developed model, the cutting carrying efficiency can be determined as follows [16]:

$$
\begin{gathered}
\eta=\frac{V_{c}}{V_{m e}} \times 100(16) \\
V_{m e}=V_{m} \frac{2 n+1}{n+1}(17) \\
V_{c}=\left[\frac{3.878 \times 10^{4}}{\rho_{\text {mud }}}\right]^{\frac{1}{2-n}}\left[\left(\frac{2.4}{D_{h}-D_{p}}\right)\left(\frac{2 n+1}{3 n}\right)\right]^{\frac{n}{2-n}}
\end{gathered}
$$

Where; $\eta=$ hole cleaning efficiency; $V_{c}=$ drilling fluid critical velocity; $\mathrm{V}_{\mathrm{me}}=$ drilling fluid effective velocity; $\mathrm{n}=$ power law index; $\rho_{\text {mud }}=$ drilling fluid density, $\mathrm{D}_{\mathrm{h}}=$ hole size; $D_{p}=$ drill pipe size.

Using the developed model will add more dimensions to predict several factors that control the drilling operations such as hole cleaning efficiency, cutting concentration in the hole, and prediction of drilling problems. There is no current model that can predict the drilling parameters in real time (every 10 to $20 \mathrm{~min}$ ) because all models depend on the laboratory measurements which are performed maximum twice a 


\section{Petroleum \& Petrochemical Engineering Journal}

day. Using the developed model we can predict real time and this can be logged with the well depth, any anomalies can be detected and mitigated immediately. This will save the cost of drilling operations and also will minimize the drilling time.

\section{Conclusion}

Non-linear regression technique was used to develop six correlations to determine the rheological parameters based on 6000 actual field measurements. The obtained correlations can be used to estimate the rheological parameters based only on Marsh funnel time and drilling fluid density with an average absolute error less than $4 \%$ and a correlation coefficient greater than 0.95. Drilling hydraulics and hole cleaning efficiency can be obtained and predicted in real time based on the developed correlations. This technique is inexpensive and will save time and will reduce the total cost of the drilling operations.

\section{References}

1. Bourgoyne AT, Chenevert ME, Millheim KK, Young FS (1991) Applied Drilling Engineering. Society of Petroleum EngineersRichardson, USA, 2.

2. Hossain ME, Al-Majed AA (2015) Fundamentals of Sustainable Drilling Engineering. In: John Wiley \& Sons Ltd (Eds.), Chichester, United Kingdom.

3. Tehrani A (2007) Behaviour of Suspensions and Emulsions in Drilling Fluids. Annual Transactions of the Nordic Rheology Society 15: 9.

4. Nguyen T, Miska S, Yu M, Takach N (2011) Predicting Dynamic Barite Sag in Newtonian-Oil Based Drilling Fluids in Pipe. J Energy Resour Technol 133(2): 10.

5. Nandurdikar NS, Takach NE, Miska SZ (2002) Chemically Improved Filter Cakes for Drilling Wells. J Energy Resour Technol 124(4): 223-230.

6. Abdo J, Haneef MD (2013) Nano-Enhanced Drilling Fluids: Pioneering Approach to Overcome Uncompromising Drilling Problems. J Energy Resour Technol 134(1): 6.
7. Power D, Zamora M (2003) Drilling Fluid Yield Stress:Measurement Techniques for Improved Understanding of Critical Drilling Fluid Parameters. AADE Technical Conference, Houston, USA.

8. Zamora M, Power D (2002) Making a Case for AADE Hydraulics and the Unified RheologicalModel. AADE TechnicalConference, Houston, USA.

9. Marsh HN (1931) Properties and Treatment of Rotary Mud. Society of Petroleum Engineers, Transactions of the AIME 92(1): 234-251.

10. Balhoff MT, Lake LW, Bommer PM, Lewis RE, Weber MJ, et al. (2011) Rheological and yield stress measurements of non-Newtonian fluids using a Marsh Funnel. J Pet Sci Eng 77(3-4): 393-402.

11. Zhang F, Miska S, Yu M, Ozbayoglu EM, Takach N (2015) Pressure Profile in Annulus: Solids Play a Significant Role. J Energy Resour Technol 137(6): 9.

12. Taghipour A, Lund B, Ytrehus JD, Skalle P, Saasen A, et al. (2014) Experimental Study of Hydraulics and Cuttings Transport in Circular and Noncircular Wellbores. J Energy Resour Technol 136(2): 1-8.

13. Owen JE (1941) A Comparison of Marsh-funnel and Stormer Viscosity of Drilling Muds. Society of Petroleum Engineers, Petroleum Technology 4(5): 19.

14. Pitt MJ (2000) The Marsh Funnel and Drilling Fluid Viscosity: A New Equation for Field Use. SPE Drilling and Completion 15(1): 3-6.

15. Almahdawi FH, Al-Yaseri, Zarzor A, Nagham N (2014) Apparent Viscosity Direct from Marsh Funnel Test. Iraqi Journal of Chemical and Petroleum Engineering 15(1): 51-57.

16. Mahmoud MA (2006) An Integrated Model for Hole Cleaning during Drilling Directional Wells. MS Thesis, Suez Canal University, Egypt. 